\title{
DAVID FOGEL NO CENTRO DA PERIFERIA
}

\author{
Moacir Amâncio 1 \\ 1Universidade de São Paulo, São Paulo, São Paulo, Brasil
}

\begin{abstract}
Resumo: Após o fim do esplendor dos tempos ibéricos medievais, dos quais os judeus participaram plenamente, sob os governos islâmicos, o renovado impulso cultural da língua hebraica somente eclodiria ao final do século XVIII, com a Hascalá ou o Iluminismo Judaico, na Alemanha. Surgiu então uma literatura hebraica na Europa, seguidora dos padrões europeus da época, em forma e conteúdo. O modelo de língua adotado pelos escritores hebreus eram a Bíblia e o Talmud. O hebraico falado renasceria só na Palestina britânica durante a primeira metade do século XX, onde as migrações judaicas iniciais planejavam fundar um novo país para viverem. Fogel e outros, ainda na Europa, fizeram a linguagem da Bíblia adquirir o sotaque da contemporaneidade.
\end{abstract}

Palavras-chave: Poesia Hebraica; Língua Hebraica; Sionismo; Modernismo; Nacionalismo e Literatura

\section{DAVID FOGEL IN THE CENTER OF THE PERIPHERY}

\begin{abstract}
After the end of the splendor throughout of medieval Iberian times under Muslim ruling in which the Jews fully participated, the renewing cultural impulse of Hebrew language would only resume at the end of the 18th century, following the launching of the Hascala or Jewish Enlightenment in Germany. Then a Hebrew literature emerged in Europe areas. The language model taken by the Hebrew writers was the accent of the Bible and the Talmud. The spoken Hebrew would appear in British Palestine only, where the first Jewish migrations planned to found a new country to living in. Fogel and others, yet in Europe, have made the language of the Bible adapt to contemporary times.
\end{abstract}

Keywords: Hebrew Poetry; Hebrew Language; Zionism; Modernism; Nacionalism and Literature 
תקציר

אחרי סוף הפאר העברי בספרד משך ימי הביניים תחת ממשלתות מוסלמיות, הרוח המתחדשת היה חוזר לשפה העברית רק בחלק האחרון של המאה מאה ה יח בעיקבות מערערת ההשכלה בגרמניה ובאזורים אחרים באירופה. מאז, הסיפרות העברית פרץ בכמה ארצות באירופה בעוצמה מפתיעה. בהתחלה המודל הם'גנוני באה מהתורה, תלמוד,מידרשים וכתבי ההחכמים. העברית המדוברת רק היתה עולה לאור בפלסטינה, בעיקר, בתקופת המנדט הבריטי, ואילו הציונים תכננו ויישמו את מדינת ישראל העת'דית. דוד פוגל וסופרים אחרים, באירופה, גרמו לשפה העבירת להסתגל לתקופה העכשווית עם ירציתיות ומקוריות אישית שהפכו לבסיס היסוד של אחת הספרותיות הפאעילות ביותר

\section{O poeta e romancista David Fogel (Satanov 1891-Auschwitz} 1944) teve uma vida trágica que, como a de certos escritores, concorre com a ficção, podendo ele se tornar uma personagem capaz de concorrer com a própria obra. Herói negativo, do ponto de vista convencional, quando a vitória está no fracasso. Aura fortíssima, ele nasceu para não dar certo mas só brilhou em sua hora póstuma. Deixou Satanov, a cidade natal, para aperfeiçoar o hebraico numa escola rabínica de Vilna e em 1912 já estava em Viena, onde, durante a Primeira Guerra Mundial, acabaria preso como russo, enquanto tinha sido preso na Rússia como desertor. Era o momento em que os judeus europeus, principalmente, se dividiam, grosso modo, entre os que apoiavam e militavam pela construção de um país na região do antigo Israel, e aqueles que se opunham à ideia lançada pelo jornalista e escritor austro-húngaro Theodor Herzl (1860-1904) ${ }^{1}$, eram atacados pelos partidários dele, por serem "impermeáveis" ao recrudescimento do antissemitismo generalizado. A mobilização de quem se engajava nessa luta era total. O momento épico exigia também uma arte comprometida. $\mathrm{O}$ haluts, o

\footnotetext{
${ }^{1}$ Herzl é considerado o criador do sionismo político, ideologia voltada para a criação de um país destinado aos judeus, submetidos a opressão e violências individuais e coletivas insufladas pelo antissemitismo oficial e popular.
} 
pioneiro, disposto a forjar um novo judeu (muito diferente daqueles que viam como passivos, segundo a ideologia da época), que se entregariam ao trabalho braçal e estariam prontos para a autodefesa. A chamada diáspora ficaria para trás. A literatura expressava essa vanguarda coletivista e exigia o engajamento dos novos autores numa arte comprometida com o objetivo político, a redenção do povo judeu no aqui e agora, deixando de lado o ideal messiânico. Fogel (pronúncia Foguel, adaptação transliterada do hebraico desse nome iídiche-alemão, ou Vogel), no entanto, escrevia poemas melancólicos, angustiados, perpassados por vezes de atmosfera decadentista. Seu primeiro livro, Mul haShaar haAfel (Diante do Portão Escuro, 1923) foi percebido e admirado num círculo que não se expandiu devido às circunstâncias. A insensibilidade era ditada mais por tendência da hora do que por desinformação sobre o próprio tempo. Shaul Tchernikhovski (Rússia 1875-Jerusalém 1943), um dos papas da poesia da época, o aplaudiu, mas seu par Chaim Nachman Bialik (Rússia 1873-Viena 1934)², o grande poeta, não entendeu a escrita de Fogel, por exemplo. Sua vida foi uma sucessão de desastres pequenos e grandes. A primeira mulher morreu tuberculosa, doença que também o acometeria. Novamente casado, passou um período na ainda Palestina com a família, o casal teve uma filha, Tamar, e retornou à Europa. Durante a Primeira Guerra Mundial havia sido preso na Áustria por ser russo, na segunda, foi preso na França por ser austríaco - obtivera a cidadania como resultado de permanência naquele país. Depois caiu nas mãos dos nazistas. Segundo depoimento da filha do poeta, Fogel morreu de um ataque cardíaco ao saltar do trem que o levaria ao campo de extermínio. Um toque poético, afinal, num gesto de resistência contra o futuro previsível. Os registros nazistas, se confiáveis, informam que ele foi morto em Auschwitz, 1944.

Além de poesia, Fogel também escreveu prosa, inclusive uma novela em iídiche, e seu romance, Vida de Casado (Chaiê

${ }^{2}$ Chaim - ch corresponde à transliteração da letra hebraica chet ( $\left.\pi\right)$, de som parecido com o do $j$ castelhano. O $h$ também é empregado para esse fim. 
Nissuin:1986), é exemplo de virtuosismo linguístico e mirada tragicômica por vezes incongruente no quadro geral da obra, o que porém ressalta o aspecto grotesco do romance, com traços impressionistas-expressionistas que se conflitam intensificando no quadro estrutural a dramaticidade da trama. Isso também se verifica em sua poesia. De qualquer modo, trata-se de realização artística extraordinária, quando se considera que o hebraico ainda engatinhava na sua recuperação como língua plena, isto é, escrita e falada, após um período de quase 2000 anos, não morta, mas pouquíssimo usada em conversação. $\mathrm{O}$ autor pertence à família, portanto, de escritores que, pela sua opção idiomática, poderiam ser chamados, por equívoco tendencioso de não-europeus, como Bialik, Yossef Chaim Brenner (Ucrânia 1881-Jafa 1921), Micha Berdichevski (Rússia 1865-Berlim 1921), Shemuel Yossef Agnon (Ucrânia1888-Jerusalém 1970), Uri Nissan Gnessin (Ucrânia 1879-Varsóvia 1913). O último foi amigo de Brenner e introdutor do fluxo de consciência na literatura hebraica, dono de uma escrita intensa em sua interioridade, que também deixou marcas definitivas em Fogel. Entre outros autores, eles produziram toda uma literatura nos moldes da época, mas em hebraico e por isso na maioria permanecem desconhecidos fora do âmbito primeiro judaico então, e hoje israelense, confinados num território quase invisível à cultura europeia. No entanto, a obra de Fogel, redescoberta a partir de 1950, contribuiu para mudar a expressão israelense quando o indivíduo começaria a conquistar seu posto na paisagem cultural do país, ainda sob os ecos do coletivismo pioneiro, no início da segunda metade do século 20.

A busca da voz intimista - determinante na poesia de David -, coincidia com a crítica à rigidez do sionismo pioneiro, quando a épica e o patriotismo davam sinais de cansaço. Um primeiro toque nesse sentido já viria bem cedo, com a novela Efraim Volta para a Alfafa" (1983: 197-244), de S. Yzhar (Israel 1916-2006), publicada no idioma hebraico em 1938. Surpreendentemente, pela maturidade e apuro técnico, trazia a assinatura de um jovem de 24 anos e colocaria de modo claro a orientação coletivista como um 
leito de Procusto. Efraim, no qibuts, está cansado de trabalhar com a alfafa e tenta ser transferido para o pomar, sem conseguir, pois a mudança abalaria as fundações da colônia rural "ortodoxa". O veio crítico se desenvolveria em capítulos até o surgimento de nova geração de escritores mais incisivos, entre eles Amós Oz (19392018), que estreou em 1965, com um livro de contos. Numa narrativa epigonal, Direção do Vento (2007:160-187), mas paródico nas suas caricaturas, do jovem Amós Oz (Israel 1939-2018), em relação ao icônico romance do ano de 1948, Ele Foi Pelos Campos (Hu Halach baSadot, 1948), de Moshê Shamir (Israel 1921-2004), confronta-se o sionismo originário, linha dura, de ideologia cerrada, com as novas gerações de israelenses que já não podiam se enquadrar no esquema pré-moldado de décadas atrás. Shimshon (Sansão), tipo de patriarca tribal, herói da coletividade e do coletivismo, era também autor ideólogo do sionismo. Homem do qibuts velha guarda, não engolia o comportamento delicado, introvertido, de seu filho Guideon, e não conseguia dominar o caçula Zak, outro rebento dele com mais uma das mulheres dos qibutsim. Envergonhado e cheio de culpa, devido à sua falha na máquina do sistema, Guideon procura dar satisfação ao pai, alista-se na aeronáutica e, no dia da prova definitiva, do triunfante salto de paraquedas sobre a área do qibuts, faz uma trapalhada, enrosca-se nos cabos de alta tensão e, por causa do medo de poucos metros mais até o solo, nega-se a cortar as correias e cair na terra, confunde-se ou, numa espécie de ato falho, toca num dos cabos (como a personagem de Shamir parece deixar a granada explodir na própria mão), provocando o circuito que o aniquila. Haveria outros textos de contestação por autores logo consagrados. Nova época.

Encerrava-se de fato o trajeto do acervo de Fogel por diversos países antes de estacionar em Israel onde ainda passaria por um túnel de silêncio até ser devolvido à luz em edições e traduções. Deve-se notar que o material parece ter sido devidamente preservado para a hora do milagre e da redenção em Sion. Komen, participante das escavações no acervo, faz lembrar a penúria da vida do autor quando informa que alguns dos seus cadernos de poemas eram ca- 
lendários reciclados (2001:13). Tudo aquilo provocaria uma febre em torno de David e sua herança literária. O notável Natan Zach, poeta, crítico, professor de literatura, agente de mudanças e rompimentos com a poesia verborrágica, patriótica, "simbolista" da primeira metade e mais do século 20 , ao pregar em favor do "poema correto", despojado, contido, "drummondiano", encontrara em Fogel o exemplo a ser seguido, nos anos 1950, com jovens escritores em Jerusalém, reunidos numa publicação modesta e vibrante, Liqrat - Rumo A (Mazor 2013:12). Fogel se tornaria modelar, depois do desprezo votado pelos senhores estabelecidos da poesia hebraica em Israel - Avraham Shlonsky (Rússia 1900-Israel 1973) e Natan Alterman (Polônia 1910-Israel 1970), este sim cantor da épica israelense. Vejam-se trechos do conhecido poema $A$ Bandeja de Prata, sob epígrafe com palavras do cientista Chaim Weitzman (Bielorussia-1934-Israel 1952)), primeiro presidente de Israel, segundo as quais um Estado não é oferecido ao povo em bandeja de prata. Note-se, o autor emprega o termo hebreus (ivriim), em vez de judeus (iehudim) conforme a ideologia vigente. Tradução minha: 


\begin{tabular}{|c|c|}
\hline 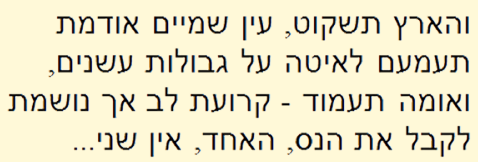 & $\begin{array}{l}\text { A terra em calma... o olho vermelho do céu } \\
\text { Escurece lentamente sobre as fronteiras em chamas. } \\
\text { A Nação aguarda - o coração rasgado, mas aspira } \\
\text { pelo milagre único, sem segundo... }\end{array}$ \\
\hline ואט אט מנגד יצאו נערה ונער הם אל מול האומה. & $\begin{array}{l}\text { Então defronte irrompem rapaz e moça } \\
\text { passo a passo aproximam-se da Nação. }\end{array}$ \\
\hline 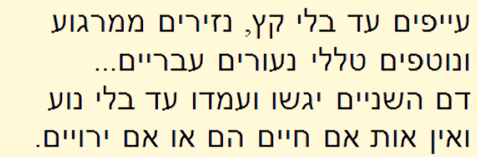 & $\begin{array}{l}\text { Cansados até os ossos, sem nenhum descanso, } \\
\text { A gotejar o orvalho da juventude hebreia... } \\
\text { Em silêncio chegam e se postam imóveis } \\
\text { Sem sinal de vida nem de tiros. }\end{array}$ \\
\hline 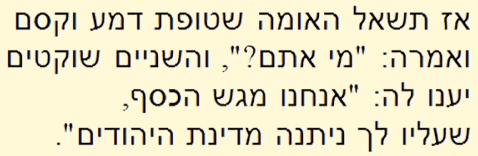 & $\begin{array}{l}\text { "Quem sois?" E os dois tranquilos respondem: } \\
\text { "Somos a bandeja de prata, na qual } \\
\text { A vós foi dado o Estado Judaico". }\end{array}$ \\
\hline כךך יאמרו ונפלו לרגלה עוטפי צול ישראל ישראל & $\begin{array}{l}\text { Dizem e caem aos seus pés, cobertos de sombra. } \\
0 \text { resto virá contado na história de Israel }\end{array}$ \\
\hline
\end{tabular}

De modo algum a polêmica reduz a importância de Shlonsky e Alterman como poetas cuja linguagem exuberante, palavrosa, chocava-se com o texto lacônico, sombrio, cético, decadentista vincado pelo expressionismo e finamente delineado pelo imagismo de Fogel numa linguagem enxuta e pontual, que contribuiria para torná-lo grande mestre do modernismo hebraico de meados do século 20. A tensão estética está presente no seguinte poema, por exemplo:

Note-se a precisão das imagens, a violência aterradora e o fantástico, o grotesco, tão pungente em sua metáfora maldita. Convenhamos, trata-se de um poema voltado para as tragédias e violências da Europa da Primeira Guerra, mas não destoa da Segunda Guerra, se for o caso de assim chamá-la, como um texto emblemá- 
tico do horror - tudo prosseguiria de maneira cíclica. Komen cita o caso de uma obra de arte plástica sobre a Primeira Guerra que serviria melhor à Segunda 2001:215). Fogel:

\begin{tabular}{|c|c|}
\hline תהתבות תקיה אין איש. כסת, & $\begin{array}{l}\text { Espadas cravadas no cobertor, } \\
\text { embaixo não há ninguém. }\end{array}$ \\
\hline בעיתנועיצת צריטה & $\begin{array}{l}\text { Balança o berço } \\
\text { por si mesmo, } \\
\text { nele uma criança morta. }\end{array}$ \\
\hline באה אלף שנה מנריץ גזרה, & $\begin{array}{l}\text { A cada mil anos } \\
\text { vem uma velha da terra condenada, } \\
\text { olha uma vez na janela }\end{array}$ \\
\hline והולכה. & e se vai. \\
\hline וינה, 25.3.1921 & Viena, 25-3-1921 \\
\hline
\end{tabular}

O modo de Fogel nesse texto, uma das suas constantes, coincide com muitos poemas da época e posteriores publicados em diversos idiomas europeus como o inglês, o alemão, o italiano, o castelhano etc. O crítico e professor israelense radicado nos Estados Unidos, Yair Mazor, assinala o papel pioneiro de Avraham ben Yitzhak Sonne (Polônia 1883-Jerusalém 1950) na literatura hebraica moderna, com seus despojados textos de recorte imagista, às vezes manchados de sombras do expressionismo, mas considera o fato de ter publicado apenas 12 poemas em vida (um deles, desprezado, por ter sofrido interferências do editor) como a causa do seu deslocamento na cena, que passaria a ser protagonizada pelo discípulo Fogel. Apesar das influências, seja de Sonne, seja de Uri Nissan Gnessin, com suas narrativas de alta voltagem poética, anunciador do fluxo de consciência na ficção europeia (embora ignorada por causa do idioma) e hebraica, da narrativa livre do enredo conven- 
cional. Mais a poderosa poesia alemã, de Rilke a Trakl (Mazor 2013:6). Mas acrescente-se a prosa de Schnitzler. A influência de tantos autores não impediu que ele acabasse por se impor, devido à sua notável originalidade na literatura hebraica que se formava para o século 20 (2013:7, passim). Inseguranças, angústias, a errância alternam entre a vida e a literatura, como se vê nos poemas aqui publicados de seu primeiro livro, Diante do Portão Escuro (1998:15-89). Não há muitos fatos explícitos nessa poesia, mas sobretudo a reverberação deles, devidamente distorcidos, ampliados, também apagados, e nisso é possível perceber a refração das experiências observadas na biografia de Fogel. Poemas na voz feminina, o que instaura óbvio conteúdo dramático, evocam suas paixões, nesse primeiro livro. Destaque àquela adolescente pela qual ele, aos 19 anos, se apaixonou, sendo correspondido, embora o caso de fato ocorresse com a mãe da mocinha - a história seria retomada no incompleto Romance Vienense (Roman Vinai, 2012). O triângulo chegou ao fim com a partida das duas heroínas para os Estados Unidos. Nos poemas de Fogel estão também o desgarramento tanto do pai quanto do filho, apontando para a desagregação de um estilo de vida conservado por séculos pelos judeus da Europa oriental, alheios e ao mesmo tempo confinados pela discriminação e hostilidades cíclicas, a infância melancólica, insolúvel como todo o resto, a família, sem perder a perspectiva da universalidade de seu trajeto, ao qual não falta uma percepção irônica e humorística. Na prosa, ele não se detém nem mesmo diante do chapliniano, como vemos na pantomima do romance Vida de Casado (Chaiê Nissuin, 2012) sobre o casamento de Rudolf, obscuro escritor judeu, e Thea, da nobreza decadente, sádica, diabólica. Fatalíssima Vênus castigadora, talvez uma alegoria da Europa que fascinava os intelectuais judeus da parte oriental do continente, e da impossibilidade do convívio pleno nesse universo que se revelaria em toda a sua frieza técnica na Shoá, pouco depois. Por desfaçatez, Thea - nome mais complexo no seu alcance do que "apenas" irônico, exige se converter ao judaísmo para casar com ele e assim espezinhá-lo com zombaria virtuosística, calculada. O livro saiu pela 
primeira vez em Jerusalém (1929). O autor tentou lançá-lo também numa tradução alemã, mas o tema foi considerado inconveniente àquela altura, provocador em excesso, por um experiente e cauteloso editor judeu. De qualquer modo, grande romance. O flanar de Rudolf por Viena é inesquecível.

A poesia do obscuro, tímido, o gauche que jamais conseguiu manter um emprego fixo, rejeitou empregos mesmo muito convenientes, vivendo de ajuda dos amigos, das refeições dos indigentes, da irmã na Rússia e algum trabalho esporádico (ensino de hebraico), contribuiu postumamente para a renovação da poesia hebraica escrita em Israel a partir dos anos 50 e 60: linguagem enxuta, alusiva, esfumada em suas pinceladas rápidas e únicas. A tensão expressionismo-impressionismo, no romance Vida de Casado, indica o nível de sofisticação estética do autor: as duas escolas, nessa síntese, fazem na palavra, a própria matéria da expressão, semelhante à tinta e o traço na pintura. Observe-se que esse imagismo-expressionismo manifesta-se com frequência também nos seus versos, quando o olho imaginário do poeta atua como o organizador - cinematográfico - do texto. A onda em torno de sua obra chegou a provocar o que se chamaria de "foguelismo", moda literária repetitiva, mas indicadora do impacto provocado pela descoberta de um escritor que permanecera submerso. O tom trágico e abrupto de diversos poemas falando de mortandades tem provocado aquelas associações com a Shoá, inevitáveis. Há certo equívoco aí, observa Mazor, embora nem tanto, como sugerido acima (2013:14). Vogel escreveu os poemas antes da Shoá, que o vitimaria. Mas viveu durante a Primeira Grande Guerra e seu morticínio inaugural do século 20. Sofreu a instabilidade do talush - aquele que não pode mais voltar para casa, e não pode encontrar uma casa em nenhum outro lugar, pois nada lhe pertence nem ele pertence a coisa alguma - dado da experiência do desenraizamento coletivo que tem nos judeus um paradigma e se tornaria uma constante da humanidade em suas transferências tanto individuais como de massa. David viveu o seu judaísmo: apático em relação ao nacionalismo, mas foi suficientemente judeu para escrever seus textos em hebraico, para 
observar e atacar o antissemitismo crescente no mundo germânico, investindo a sua imaginação, a sua ironia, o seu dilaceramento, na transfiguração da realidade feita linguagem. Poderia ter ficado em Israel, para onde seguiu com a mulher no ano de 1927, graças ao apoio dos amigos. Lá, foi bem recebido e lhe ofereceram o emprego de professor de literatura hebraica em Haifa, mas ele, coerência fatal, refugou, preferindo retornar à Europa, onde o choque foi geral. Talvez como Walter Benjamin, que recusou possibilidades de se transferir para Jerusalém ou São Paulo, o poeta se visse mais estrangeiro ainda fora daquele continente.

Paralisia (análoga ao silêncio, à morte, ao sono, ao êxtase) e movimento se alternam nessa obra em prosa e verso, desconjunto de modalidades do instável. Um poema fala no voo de uma borboleta, outro, nos passos indecisos de uma sonâmbula, as sombras parecem agir por conta própria e os trens representam abalos interrogativos. O rolar flanante do escritor Rudolf por Viena ilustra muito bem o estranhamento daquele que caminha ao longo das ruas, passa por pessoas, prédios, vitrines que parecem pertencer a ele, mas ele está fora disso tudo. Sempre às margens da cidade, mesmo no centro delas, flutua na periferia. O mesmo ocorre com aqueles que vagam pelos ermos, sem referências, sem o sentimento de pertença. É como se olhasse pela janela de um veículo em viagem. A paisagem se move, o tempo e as coisas, pessoas, objetos, mercadorias, aproveitáveis e inúteis. Essa percepção nada tem a ver com o fascínio pela velocidade mecânica e sim com o espanto do animalesco a se articular na máquina que reconfirma o humano em sua mecanicidade. Komen assinala na obra de Vogel o significado ominoso daquele grande meio do transporte de carga e das massas humanas em constante deslocamento. Maravilha da técnica à disposição da logística, qualquer logística, o trem, seria eficaz na viabilização do extermínio em nível industrial, juntamente com outros dúbios avanços tecnológicos do tempo dos assassinos proclamado por Rimbaud. 


\section{Cinco poemas}

O primeiro encontro meu com a arte de David Fogel, ocorreu na primeira década do século 21, seguindo-se o mergulho em sua obra e os primeiros ensaios de tradução datados de 2012 quando, tomado pelo espírito fogeliano, acompanhei vida e obra do escritor direta e indiretamente, tocado pela sua poesia e prosa. Levei poemas seus para ler e traduzir numa viagem que passou por Viena. Lá, às margens do Prater, num local onde à noite se avistavam algumas prostitutas fazendo ponto, eu me dediquei aos textos dele. Talvez o jeito de me situar na cidade e discreto Qadish ${ }^{3}$ em memória do autor. Aqui estão amostras da poesia de Fogel, parte do livro Diante do Portão Escuro:

Tabela 1: Fragmentos do livro Diante do Porão

\begin{tabular}{|c|c|}
\hline עיפרף הגישם תמהון בהיר & $\begin{array}{l}\text { Após a chuva, } \\
\text { um luminoso espanto pairou } \\
\text { sobre os campos tremulantes. }\end{array}$ \\
\hline רין קהרי דתר כהה דה היור. & $\begin{array}{l}0 \text { vento escuro cavava } \\
\text { Entre as dobras de pálida bandeira. }\end{array}$ \\
\hline ובין אשכלות נצה סגולה. & E entre os cachos brotou uma violeta. \\
\hline 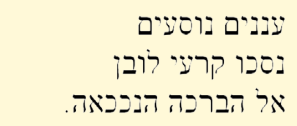 & $\begin{array}{l}\text { Nuvens viajantes } \\
\text { deitavam farrapos de brancura } \\
\text { pelo lago triste. }\end{array}$ \\
\hline תורעפי גוג דמיטי אדומים & $\begin{array}{l}\text { E as telhas } \\
\text { vermelhas riam } \\
\text { entre lágrimas. }\end{array}$ \\
\hline
\end{tabular}

${ }^{3}$ Qadish, ou Kadish, oração judaica, declaração de fé diária na sinagoga e proferida por um parente no lugar de uma pessoa morta para desse modo confirmar a permanência de sua fé judaica. 


\begin{tabular}{|c|c|}
\hline 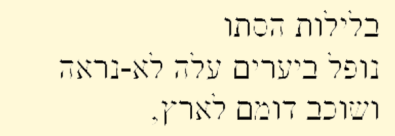 & $\begin{array}{l}\text { Pelas noites de outono } \\
\text { cai nos bosques uma folha não vista } \\
\text { e inerte jaz no solo. }\end{array}$ \\
\hline 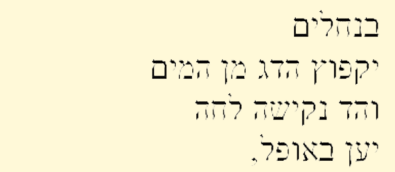 & $\begin{array}{l}\text { Nos rios } \\
\text { salta o peixe das águas } \\
\text { e o eco do choque molhado } \\
\text { responde na treva. }\end{array}$ \\
\hline 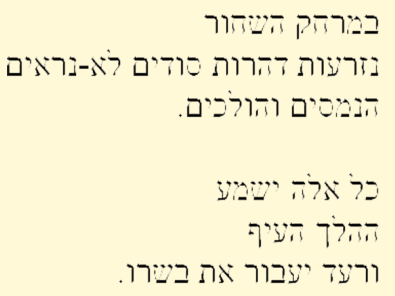 & $\begin{array}{l}\text { Na distância negra } \\
\text { semeia-se o galope de cavalos invisíveis } \\
\text { que dissolvem e se vão. } \\
\text { Tudo isso escutao caminhante cansado } \\
\text { e um tremor atravessa a sua carne. }\end{array}$ \\
\hline 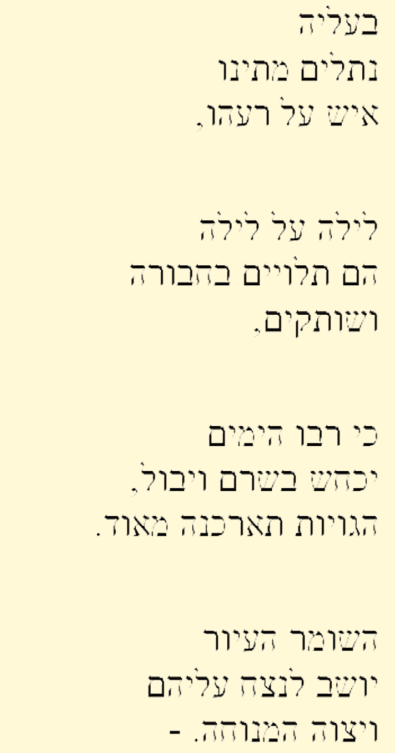 & $\begin{array}{l}\text { No sótão } \\
\text { pendem os nossos mortos nus } \\
\text { um sobre o outro. } \\
\text { Noite após noite } \\
\text { eles pendem juntos } \\
\text { e se calam. } \\
\text { Conforme aumentam os dias } \\
\text { a carne deles fenece e esvai. } \\
\text { Os corpos se alongam muito. } \\
\text { 0 vigia cego } \\
\text { guarda-os pela eternidade } \\
\text { e ordena o repouso. - }\end{array}$ \\
\hline
\end{tabular}




\begin{tabular}{|c|c|}
\hline עיקים יהכונות טהורים לרבבות & $\begin{array}{l}\text { Caixões negros aos milhares } \\
\text { esperam vazios } \\
\text { na face da terra. }\end{array}$ \\
\hline 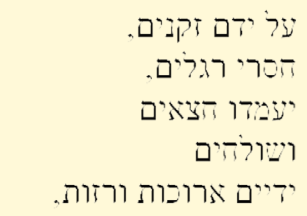 & $\begin{array}{l}\text { Ao lado deles, velhos } \\
\text { sem pernas } \\
\text { mantém-se pela metade, } \\
\text { com as mãos } \\
\text { longas e magras estendidas. }\end{array}$ \\
\hline 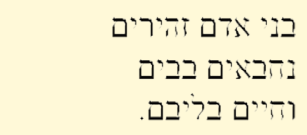 & $\begin{array}{l}\text { Pessoas precavidas } \\
\text { ocultam-se dentro das casas } \\
\text { e vivem nos seus corações. }\end{array}$ \\
\hline 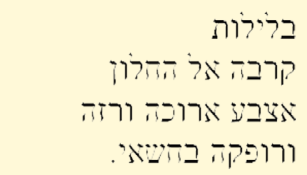 & $\begin{array}{l}\text { Às noites, } \\
\text { chega à janela } \\
\text { um vulto longo e magro, } \\
\text { bate em segredo. }\end{array}$ \\
\hline
\end{tabular}

Fonte: Fogel 


\begin{tabular}{|c|c|}
\hline 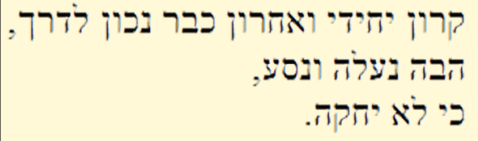 & $\begin{array}{l}\text { Um único e último vagão já está pronto para partir, } \\
\text { subamos e viajemos, } \\
\text { pois ele não espera. }\end{array}$ \\
\hline ראיתי נ:ערות רכות ברכתן & Vi jovens tenras a caminho \\
\hline ופעיהן הצרים & e seus rostos tristes \\
\hline האדינו ואבדו & ruborizados e enlutados \\
\hline כשקיות ארגיןן, & como o crepúsculo púrpura. \\
\hline ילדים עבולים וורודים & - Crianças roliças e rosadas \\
\hline שהרכו לתומים, & que candidamente seguiram, \\
\hline כי עקראו, & pois eram chamadas. \\
\hline ראיתי אבשים, & Eu vi pessoas \\
\hline גאים וזקופים تצרו ברהובות-תבר, & altivas e empertigadas pelas ruas do mundo, \\
\hline עיניהם המדולות הירהיקו & os grandes olhos delas se distanciavam \\
\hline ניאצים והלאה - & delas mesmas e mais - \\
\hline גם הניה כבר צלו בעהת & e elas também, tranquilamente, já subiram \\
\hline וי"עון, & e viajaram. \\
\hline אהרועים אבהעו, & Nós somos os últimos, \\
\hline היום יירוב, & já escurecendo, \\
\hline קרון יהידי ואהרון כבר נכון לדרך, & um único e último vagão já está pronto para partir \\
\hline הבה ע:לה דומים & vinde, subamos em silêncio, \\
\hline וביסע אף אבו, & viajemos também, \\
\hline בי לאייהכהות - & pois ele não espera. - \\
\hline
\end{tabular}




\section{Referências}

Alterman,Natan, https://shironet.mako.co.il/artist?type=lyrics\&lang =1\&prfid $=743 \&$ wrkid $=4982$.

Fogel, David, Col haShirim (Toda a Poesia). Hakibutz Hameuhad: Tel Aviv, 1998.

Fogel, David, Chaiê Nissuin (Vida de Casado). Hakibutz Hameuhad: Tel Aviv, 1986.

Fogel, David, Beveit haMirpá (No Sanatório). HaKibutz Hameuhad: Tel Aviv, 2008.

Fogel, David, Col haShirim (Toda a Poesia). Kibutz haMeuhad: Tel Aviv, 1988.

Fogel, David, Roman Vinai (Romance Vienense). Am Oved: Tel Aviv, 2012.

Gnessin, Uri Nissan, Etsel (Junto A), Iehidav/Agudat HaSoferim, Tel Aviv, $1965,4^{a}$. Reimpressão.

Komen, Aharon, HaOfel vehaPele (A Escuridão e a Maravilha), Universitat Heifa/Zmora Bitan, 2001), Haifa-Tel Aviv.

Mazor, Yair. Nocturnal Lament - The Poetry of David Fogel (Lamento Noturno, A Poesia de D.F.), Maven Marks Books: Milwaukee, 2013.

Oz, Amós; Nadine Gordimer (org.). Contando Histórias. Companhia das Letras: SP, 2007.

Shamir, Moshê. Ele Foi Pelos Campos (Hu Halach baSad). Sifriat Poalim: Tel Aviv, 1948. 
Yzhar, S. Geração da Terra (Rifka Berezin, org.), Summus Editorial, SP, 1983.

Recebido em: 10/09/2019

Aceito em: 08/11/2019

Publicado em dezembro de 2019

Moacir Amâncio. E-mail: moaman@globo.com

ORCID: https://orcid.org/0000-0001-5086-2563

Cad. Trad., Florianópolis, v. 39, n $^{0}$ esp., p. 280-296, set-dez, 2019 